\title{
International students' university preferences: how different are Malaysian and Chinese students?
}

\begin{abstract}
Purpose: The purpose of this paper is to determine factors that influenced international university preference, looking at country of origin $(\mathrm{COO})$, that is the $\mathrm{COO}$ of the course and program modes (PMs). This study specifically focusses on differences in perceptions across students from Malaysia and China. Design/methodology/approach: Conjoint analysis was used to examine the relative importances and part-worth scores of these attributes on international university preferences. Findings: PM and country of design (COD) had a major influence on Malaysian and Chinese studentsô preferences for international universities. Online distance learning was the least preferred option, while offshore campuses were more acceptable to Malaysian students compared to Chinese students. Malaysian students preferred to study in the UK, while Chinese students favored Australia. Malaysian students were also found to be more cost sensitive compared to Chinese students, while the latter were more motivated by job prospects offered by an institution. Research limitations/implications: Limitations include the specific sample, pre-university students only from developed countries (Malaysia and China), which limits the generalizability to students from other countries. Practical implications: This study offers insights in the effect of COD and PM on studentsô preferences for international universities, as well as other previously studied university-level attributes in a higher education setting. With a better understanding of factors affecting these preferences, higher educational institutions are better placed to implement a suitable marketing strategy to attract more international students. Originality/value: This study examines the impact COD, Delivery Mode (DM) and other university level attributes have on Malaysian and Chinese pre-university students' preferences for international universities. COD and DM were found to be extremely important factors that dominated the students' preferences. The study highlights the need to focus on different university attributes in different markets and to consider COD and DM issues in order to gain a larger market share of international students.
\end{abstract}

Keyword: Country of design; Delivery mode; Higher education marketing; International students; Online distance learning 